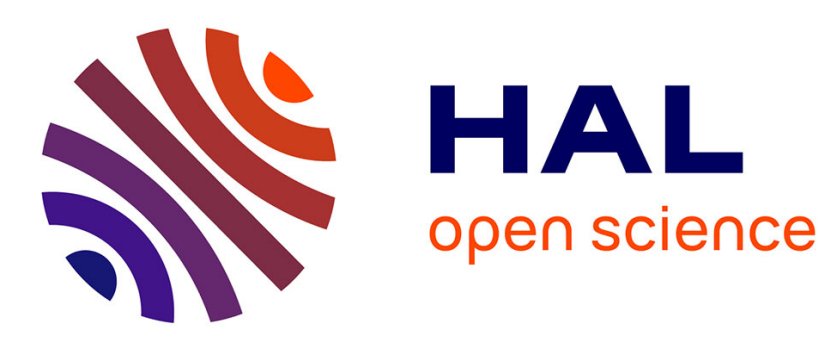

\title{
HACEK endocarditis: state-of-the-art
}

Matthieu Revest, Gérald Egmann, Vincent Cattoir, Pierre Tattevin

\section{To cite this version:}

Matthieu Revest, Gérald Egmann, Vincent Cattoir, Pierre Tattevin. HACEK endocarditis: state-of-the-art. Expert Review of Anti-infective Therapy, 2016, 14 (5), pp.523-530. 10.1586/14787210.2016.1164032 . hal-01296779

HAL Id: hal-01296779

https://hal-univ-rennes1.archives-ouvertes.fr/hal-01296779

Submitted on 10 Jun 2016

HAL is a multi-disciplinary open access archive for the deposit and dissemination of scientific research documents, whether they are published or not. The documents may come from teaching and research institutions in France or abroad, or from public or private research centers.
L'archive ouverte pluridisciplinaire $\mathbf{H A L}$, est destinée au dépôt et à la diffusion de documents scientifiques de niveau recherche, publiés ou non, émanant des établissements d'enseignement et de recherche français ou étrangers, des laboratoires publics ou privés. 


\section{HACEK endocarditis: state-of-the-art}

\section{Matthieu Revest ${ }^{1}$, Gérald Egmann ${ }^{2}$, Vincent Cattoir ${ }^{3}$, and Pierre Tattevin ${ }^{1}$}

${ }^{1}$ Infectious Diseases and Intensive Care Unit, Pontchaillou University Hospital, Rennes;

${ }^{2}$ Department of Emergency Medicine, SAMU 97.3, Centre Hospitalier Andrée Rosemon,

Cayenne; ${ }^{3}$ Bacteriology, Pontchaillou University Hospital, Rennes, France

†Author for correspondence: Prof. Pierre Tattevin, infectious Diseases and Intensive Care Unit, Pontchaillou University Hospital, 2, rue Henri Le Gull!cux, 35033 Rennes Cedex 9, France Tel.: +33299289564

Fax.: + 33299282452

pierre.tattevin@chu-rennes.tr 


\section{Abstract}

The HACEK group of bacteria - Haemophilus parainfluenzae, Aggregatibacter spp. (A. actinomycetemcomitans, A. aphrophilus, A. paraphrophilus, and A. segnis), Cardiobacterium spp. (C. hominis, C. valvarum), Eikenella corrodens, and Kingella spp. (K. kingae, K. denitrificans) are fastidious gram-negative bacteria, part of the normal microbiota of oral and upper respiratory tract in humans. Although their pathogenicity is limited, they are responsible for $1-3 \%$ of all infective endocarditis. HACEK endocarditis mostly affect patients with underlying heart disease or prosthetic valves, and are characterized by an insidious course, with a mear dragnosis delay of 1 month (Haemophilus spp.) to 3 months (Aggregatibacter and Cardiobacterium snn.). The advent of continuously monitored blood culture systems with enriched media ras erased the need for extended incubation for the diagnosis of HACEK endocarditis Medical treatment relies on third generation cephalosporin, with a favourable outcome in 80-50\% of cases, with or without cardiac surgery.

Key words: Infective endocarditis: HACEK group; Haemophilus parainfluenzae; Aggregatibacter spp.; Cardiobacteriım spp., Eikenella corrodens; Kingella spp. 


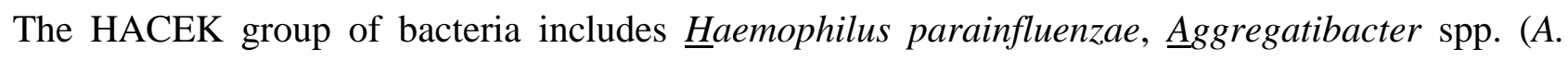
actinomycetemcomitans, A. aphrophilus, and A. segnis), Cardiobacterium spp. (C. hominis, C. valvarum), Eikenella corrodens, and Kingella spp. (K. kingae, K. denitrificans). These fastidious gram-negative bacteria share several common characteristics (Table 1): i) they all require - or are stimulated by - the presence of $\mathrm{CO}_{2}$, with optimal growth achieved only on enriched media (e.g., as those currently in use for continuously monitored automated blood culture systems) [1]; (i) they are part of the normal human microbiota, mostly oropharyngeal, but also urogenital for sorne of them; iii) they are associated with infective endocarditis (IE) [2]. This latter is partifularly salient, given that most bacteria (>80\%) associated with IE are gram-positive [3], and that hacteria from the HACEK group are very rarely encountered in infectious diseases otier than I In humans [4], with the exception of Kingella kingae, the main cause of septic arhritis in children below 2 years of age [5].

The HACEK group is responsible for 1.2-3\% of all IE cases 112 6-9]. Interestingly, the proportion of IE caused by HACEK seems to be lower in North America (0.3\%), than in other parts of the World (2\%) [8]. The relative proportion of eact etiologic agent within the HACEK group is as follows: H. parainfluenzae (27,35\%), A. actinomycetemcomitans (20\%), A. aphrophilus (12-16\%), A. segnis (1\%), C. hominis (13-27\%), C. valvarum (1\%), E. corrodens (4-5\%), K. kingae (3-7\%), and $K$. denitrificans (1\%) [2 7 . The mean age of patients with HACEK endocarditis (43-48 years) is usually lower than that of patients suffering from non-HACEK IE [2 7 9]. Of importance, the delay between symptoms onset and diagnosis is particularly long (i.e. between 2 weeks and 6 months), which may be related to the clinical presentation of HACEK IE, usually subacute. Main predisposing factors are pre-existing heart disease (60\%), and poor dentition/previous dental prosedure (58\%) while IE preferentially occurs in patients with native valves (65-80\%) [2 79 ]. Aortic (30-49\%), and mitral (45-50\%) valves are most commonly involved [2 7 9]. Surgical cardiac replacement is performed in $40 \%$ patients, and the overall outcome is favourable in most cases (8789\%) [2 7]. 
Several recent microbiological evolutions are remarkable: i) the development of enriched blood cultures (BC) media and the implementation of automated BC systems, that has erased the need for extended incubation for the diagnosis of HACEK IE [10 11]; ii) easier and reliable identification from cultures thanks to the MALDI-TOF mass spectrometry technology regardless of the system used (Microflex LT [Bruker Daltonics] or Vitek MS [bioMérieux]), with species- and genus tevel identification in 66-93\% and 88-95\% cases, respectively [12-15]; iii) rapid molecular based detection directly from clinical specimens using home-made protocols or commercially-available kits [16 17]; and iv) recent clinical and laboratory standards institute (CLSI recommendations for antimicrobial susceptibility testing of the HACEK group using the broth micrndilution technique [CLSI M45-A2 2010].

\section{Haemophilus parainfluenzae}

H. parainfluenzae is the most common cause of $\mathrm{HACE}$ K endocarditis, found in 28 (36\%) of the 77 cases of HACEK endocarditis enrolled within the International Collaboration on Endocarditis (ICE) prospective cohort study during years 2000-2006 [7], and 12 out of 45 (27\%) cases of HACEK IE reported from the Mayo Clinic jin Recisester, during years 1970-1992 [2]. The association between H. parainfluenzae bacterernia and Is is strong, with a positive predictive value (PPV) for the diagnosis of IE estimated at $55 \%(10 / 18)$ [4].

\section{Microbiology}

H. parainffuenzae is a small, non-motile, non-spore-forming, non-acid-fast, pleomorphic gramnegative hacilli, which requires for growth $\mathrm{V}$ factor or nicotinamide (complexed as NAD or NADP) present in erythrocytes. Members of the Pasteurellaceae family, Haemophilus spp. are part of the normal upper and lower respiratory tract microbiota, $H$. parainfluenzae accounting for $75 \%$ of Haemophilus species in both oral cavity and pharynx. H. parainfluenzae has very rarely been associated with human infections and most case reports of non-IE infections were related to its primary reservoir, respiratory tract (e.g. sinusitis, bronchitis, otitis, exacerbation of chronic 
obstructive pulmonary disease, pneumonia), although $H$. parainfluenzae brain abscess, surgical site infections, soft tissue infections, prosthetic joint infections, and hepatic and biliary tract infections have also been documented [18] . H. parainfluenzae may also be part of the genital tract microbiota, and documented cases of chorio-amniotitis, and neonatal sepsis have been reported.

A Canadian study of 37 clinical isolates of $H$. parainfluenzae originating from blood cultures, or abscess fluid, found susceptibility rates of $67.6 \%$ for penicillin, $97.3 \%$ for ampicillin, an $100 \%$ for amoxicillin-clavulanic acid, ceftriaxone, meropenem, and levofloxacin [19].

\section{Characteristics of $\mathbf{H}$. parainfluenzae endocarditis}

A series of 26 cases of $H$. parainfluenzae endocarditis was reported jn 1997 associated with a literature review of 26 additional cases [20]. Most patients (60\% in tie series) had underlying native valve disease, the remaining predisposing factors being prosthetic valve (12\%), or previous infective endocarditis (10\%). Of note, only one patient (2\% of all cases of Haemophilus spp. endocarditis reported in this series) was an intravenous urrag user (IVDU), while 38\% of previously reported cases (15/40) occurred in IVDU. Portal of encry remained unknown in $75 \%$ of all cases. The mean duration from symptoms oñset to diagnosis was quite long, at 34 days (range 2-330) in the series, and 37 days (range 5-365), for the cases previously reported. This diagnosis delay, possibly related to the insidious onset of symptoms and the subacute clinical course, may be one of the reason behind ture high proportion of patients who present with symptomatic peripheral embolization ( $-50 \%$ ), and large vegetation(s), $>10 \mathrm{~mm}$ in $42 \%$ of cases [20 21]. On the other hand, the proportion of patients with perivalvular abscess (7\%), and heart failure (15-30\%) is rather low as compared to usual figures in infective endocarditis, which may be related to the limited pathogenicity of these organisms. The mitral valve is most commonly affected in non-IVDU patients (71\%), while the tricuspid valve is primarily involved in IVDU (45\%). Data from two different cohorts suggested that $H$. parainfluenzae endocarditis was less likely to have an insidious onset than A. actinomycetemcomitans and C. hominis [2 7].

Despite the diagnosis delay, and the high proportion of patients with large vegetation(s), and/or 
peripheral embolization, the overall prognosis of patients with $H$. parainfluenzae endocarditis is favourable in most cases: attributable mortality was estimated at $5 \%$ in the largest series reported to date [20], and $10 \%$ in the literature review. Surgical valvular replacement was performed in $40-70 \%$ of cases. Most patients have been treated with a $\beta$-lactam agent (mostly third-generation cephalosporin during recent years [7], in agreement with international guidelines [22]). However, the outcome of medically treated patients was also favourable in most cases in older series, when amoxicillin and ampicillin, usually combined with an aminoglycoside, were more commonly used [2 20].

\section{Aggregatibacter spp.}

The three species A. actinomycetemcomitans, A. aphrophilus, and A segnis are the second most common cause of HACEK endocarditis, found in 26 (31\%) of the 77 cases of HACEK endocarditis enrolled within the ICE prospective cohort study [7], and 16 out of 45 (36\%) cases of HACEK endocarditis reported from the Mayo Cliric ? ?]. The association between Aggregatibacter spp. bacteremia and endocarditis is strong, wilh a PPV for the diagnosis of IE estimated at 100\% (22/22) for A. paraphrophilus and A. actiriomycetemcomitans, and 55\% (5/9) for A. aphrophilus, in a landmark New Zealand studiy [1].

\section{Microbiology}

Aggregatibacte: sp. also belong to the Pasteurellaceae family and are facultatively anaerobic, non-motile coccoid to rod-shaped, gram-negative bacteria. They are part of the normal microbiota of the human oral cavity, especially dental plaque. The genus Aggregatibacter was created in 2006, bringing, together several former species of the Actinobacillus (A. actinomycetemcomitans) and Hcemophilus (H. aphrophilus, H. paraphrophilus, and H. segnis) genera [23]. Note that the former species $H$. paraphrophilus corresponds now to $\mathrm{V}$ factor-dependent $H$. aphrophilus strains and is now classified within the species A. aphrophilus [23]. A. actinomycetemcomitans is particularly common in the gingival and supragingival crevices, and is a frequent cause of aggressive 
periodontitis [24]. In addition, as inferred from its name, A. actinomycetemcomitans is commonly isolated concomitantly with members of the Actinomycetes group in abscess and wound specimens from actinomycotic lesions [25]. A. paraphrophilus is a normal inhabitant of the nasopharynx, oropharynx, mouth, lower gastro-intestinal tract, and vagina of mature women. Besides IE, A. paraphrophilus has mainly been documented from abscess (especially brain abscess), but also bone or joint infections, and endophtalmitis [18]. Likely underestimated due to misidentificaticns by conventional methods, A. segnis may also cause endocarditis as well as bacteremia and pyelonephritis [26 27].

A study of 11 clinical isolates of A. aphrophilus found susceptibility rates $018 \%$ tor penicillin, and 100\% for ampicillin, amoxicillin-clavulanic acid, ceftriaxone, meropenern, and levofloxacin [19]. Of note, the only HACEK organism resistant to penicillin in the ICE-prospective cohort study was one isolate of A. aphrophilus [7].

\section{Characteristics of Aggregatibacter spp. endocorditis}

The first case of A. actinomycetemcomitans endocarditis was published in 1964, and a literature review of 102 cases of A. actinomycetemcomitans endocarditis published 40 years later found that: i) A. actinomycetemcomitans endiocarcitis mostly occurred in men (two thirds of all reported cases), with a mean age of 47 year; ;i) risk factors mostly included underlying valve disease (75\% of all cases, secondary to illeumatic heart disease in half of patients), and prosthetic valve (26\%); iii) a dental disease was frequently associated (42\%); iv) the disease was particularly insidious, with a mean diagnosis delay of 13 weeks after symptoms onset; v) the aortic valve was more commonly affected (51\%), than the mitral valve (33\%); vi) complications were not rare (63\%), and mostly includec emboli (30\%), and heart failure (27\%); vii) surgical valvular replacement was required in $25 \%$ of cases, and viii) the overall mortality rate was $18 \%$ [28]. When compared to other HACEK endocarditis within the ICE-prospective cohort study, A. actinomycetemcomitans endocarditis was more likely to occur on prosthetic valves $(10 / 15,67 \%)$, with a diagnosis delay $>$ one month $(8 / 15$, 53\%), and to be associated with Osler's nodes [7]. 
Other Aggregatibacter species are less common causes of endocarditis, and available data remain scarce: A review of 23 cases of A. aphrophilus endocarditis published in 1975 - then referred to as Haemophilus aphrophilus - was remarkable for the high mortality rate (48\%) [29]. A review of 17 cases of A. paraphrophilus endocarditis published in 1995 - then referred to as Haemophilus paraphrophilus - was remarkable for the predominance of mitral valve endocarditis (16/17), while the mortality rate was in the usual range for IE, at $18 \%$ [30].

\section{Cardiobacterium spp.}

Cardiobacterium spp. are the third most common agents responsible for $\mathrm{H} A \mathrm{ACEK}$ endocarditis, found in 11 (14\%) of the 77 cases of HACEK endocarditis enrolled within the ICE prospective cohort study [7], and 12 out of 45 (27\%) cases of HACEK endocardicis reported from the Mayo Clinic [2]. Although C. hominis is by far the most common Cardiobacterium species involved, a few cases of $C$. valvarum endocarditis have been reported since it was first identified in a patient with bicuspid aortitis and ruptured mycotic cerebrai aneurysm, in 2004 [31]. The association between C. hominis bacteremia and endocarditis is strong, with a PPV for the diagnosis of endocarditis estimated at 88\% (7/8) in ene study [4], and 94\% (32/34), or 95\% (60/63) in two large literature reviews [32 33].

\section{Microbiology}

Cardiobacterium spp. belong to the Cardiobacteriaceae family and consist of facultatively anaerobic. hon-motile, gram-negative rods. After gram staining, they appear as pairs, short chains, teardrop forms, rosettes, or clusters - sometimes with bulbous ends. The normal habitat of these species is the human oral cavity and nasopharynx. Cardiobacterium spp. have also been isolated from the genital tract of asymptomatic women. These organisms are of low virulence, and their pathogenic effect is mostly limited to IE in humans. Inocula as great as $10^{9}$ microorganisms injected into various mice, rabbits, hamsters, guinea pigs, and pigeons, failed to produce any evidence of infection [33]. Note that one case of prosthetic valve endocarditis was reported following upper 
gastrointestinal endoscopy [34].

Although most clinical isolates of Cardiobacterium spp. investigated to date were susceptible to penicillin and ampicillin, rare reports of $\beta$-lactamase-producing $C$. hominis strains causing endocarditis [35 36], have led to the recommendation that third-generation cephalosporins must be considered as the first-line antibacterial treatment of Cardiobacterium spp. endocarditis.

\section{Characteristics of Cardiobacterium spp. endocarditis}

In 2005 and 2006, two large reviews of 63 and 67 cases of C. hominis endocarditis were reprorted [32 37]. The main characteristics of $C$. hominis endocarditis are as follows. i) patients mean age was $50.2 \pm 15$ years (range, 17-82), with a male-to-female sex ratio of 2 ; ii) most common risk factors were underlying valve disease (61\%, mostly congenital heart disease and rheumatic fever), and prosthetic valve (28\%); iii) C. hominis endocarditis may be even more insidious than other HACEK endocarditis, with a mean diagnosis delay of 132 — 120 days according to Malani et al. [32], and 169 days according to Wormser et al. [33]; iv) the aortic valve is most commonly affected (52\%), followed by the mitral valve (44\%); v) main complications were heart failure (40\%), and central nervous system emboli (21\%); vi) valve replacement was required in 27 cases (45\%), and the outcome was favourable in most cases (93\% overall; 94\% for the subgroup of patients with prosthetic valve endocarditis, [32] I imited data on C. valvarum endocarditis would suggest that large vegetations and extensive valvular destruction are common [38].

\section{Eikenella corredens}

The genus Eikenella, within the family Neisseriaceae, includes the unique species E. corrodens. It is a facultatively anaerobic, non-motile, straight gram-negative small rod with rounded ends. It is a normal inhabitant of oral cavities of humans and some mammals from which it can be transmitted via saliva (bites, syringes). The prevalence carriage is higher among people under 20 years of age, and in those with periodontal disease.

Its association with endocarditis is rather weak, as i) this bacteria was responsible for only 5\% of 
all HACEK endocarditis reported from the Mayo clinic [2], and in the ICE-prospective cohort study [7]; ii) the PPV of E. corrodens bacteremia for the diagnosis of endocarditis is the lowest among all HACEK bacteria (none of 11 consecutive cases of E. corrodens bacteremia was related to endocarditis in one study) [4]; iii) E. corrodens is involved in a broad spectrum of infectious diseases, including localized infections of the head and neck, upper or lower tract respiratory infections, subcutaneous abscesses, cellulitis, and osteomyelitis [39]. Interestingly, these latter hive been especially reported following clenched fist injuries or human bites, due to the tratinatic inoculation of E. corrodens originating from the oral microbiota [40]. In addition, IVDU is a risk factor for skin and skin structure or endovascular E. corrodens infections, due to the use of saliva for skin cleansing or dissolution of narcotics in some settings [41]. Endøcaráitis represented only $2 \%$ of all invasive infections due to E. corrodens in one study [39].

A study of 17 clinical isolates of E. corrodens found susceptibility rates of $94 \%$ for penicillin and ampicillin, and $100 \%$ for ampicillin-sulbactam, anioxicillin-clavulanic acid, ceftriaxone, meropenem, and levofloxacin [19].

\section{Kingella spp.}

Kingella spp. are also mernbers of the Neisseriaceae family and consist of facultatively anaerobic, non-motile, short gran-negative rods with tapered ends. Occasionnally, they may be resistant to decolorization and appear as gram-positive bacteria. They are part of the normal microbiota of upper respiratory and genitourinary tracts in humans. Within the genus, $K$. kingae is the main spectes responisible for invasive diseases, although cases of $K$. denitrificans endocarditis have been reported [7]. K. kingae colonizes the oropharynx - but not the nasopharynx - of approximately $10 \%$ of children aged from 6 months to 4 years [5], and may be transmitted via respiratory droplets between family members and other close contacts

As for E. corrodens, its association with endocarditis is rather weak, as i) this bacteria was responsible for 7\% of HACEK endocarditis diagnosed during years 1970-1993 at the Mayo clinic 
[2], and 5\% in the ICE-prospective cohort study (2000-2006) [7]; ii) the PPV of K. kingae bacteremia for the diagnosis of endocarditis was estimated at 42\% (8/19) [4]. The situation is strikingly different for young children (i.e., under four years of age), who are much more prone to Kingella spp. invasive diseases [5]: K. kingae is the most common cause of septic arthritis in this population, which may be related to a potent repeats-in toxin system (RTX), that exhibits a wite range of cytotoxic activity and is particularly deleterious for macrophages, leucocytes, aria syno ial cells [42]. A study of 143 consecutive patients with K. kingae infections diagnosed in southern Israel during years 1988-2013 found that septic arthritis, osteomyelitis or tericsynovitis were most commonly involved (55\%), followed by occult bacteremia (39\%). Only cwo natients (1\% of all invasive K. kingae infections) were diagnosed with endocarditis [42].

However, given the very low incidence of infective endocarditis in children, a literature review found that K. kingae was the most common cause of HACEK enciocarditis in this population, at the same level as $H$. parainfluenzae (36\% of all HACEK eñdocarditis). Children with K. kingae endocarditis had underlying heart disease in 62\% of cases (mostly congenital), and 12/13 initially survived (92\%), although two had neüirelogical sequels (hemiplegia), and one died during cardiac surgery three months later [43] Qutbreaks of invasive infections due to $K$. kingae have been reported in children communities, with severe manifestations - including endocarditis and meningitis - and high prevalence of colonization, suggesting that some isolates may present with enhanced colonitzation fitness, increased transmissibility, and high virulence [44].

\section{Expert commentary}

Althorgh HACEK endocarditis has been first reported more than 50 years ago, and remains a rare clinical entity, totalling around 1-3\% of all infective endocarditis [7 21 45-47], this state-of-the-art paper is justified by the new findings gathered over the last decade in the fields of taxonomy, clinical presentation, diagnosis, and treatment:

- Firstly, taxonomic revisions in the genera Haemophilus and Actinobacillus have resulted in the 
description of the genus Aggregatibacter in 2006 which, by chance, did not change the acronym 'HACEK', but introduced some movement within some letters: While the ' $H$ ' initially referred to H. parainfluenzae, $H$. aphrophilus, and $H$. paraphrophilus, these two latter are now combined within a unique Aggregatibacter species, A. aphrophilus. In addition, A. actinomycetemcomitans was reclassified within the Aggregatibacter genus, which also comprises A. segnis (fornerty Haemophilus segnis). Hence, the HACEK group now refers to H. parainfluenzae, Aggregatibacter spp. (A. actinomycetemcomitans, A. aphrophilus, and A. segnis), Cardiobacterium sp?. IC. hominis, C. valvarum), Eikenella corrodens, and Kingella spp (K. kingae, K. denitrificans) [18].

- Secondly, the advent of continuously monitored automated blood cuiture systems with enriched media have changed the paradigm that the diagnosis of HACEK bioorisiream infections would require extended incubation of blood cultures: Indeed, various studies have found that $>99 \%$ of the HACEK responsible for endocarditis will be recovered within the standard 5-day incubation protocol [48]: Baron et al. analysed data from $1995-1997$ at the Standford University Medical Hospital during which time a special endo arditis blosd culture protocol with extended incubation (up to 6 weeks) was implemented follerwing phiysician requests in 215 patients: The 24 HACEK bacteria identified during that inne (out of $\sim 14,000$ routine blood cultures), were all recovered within the standard 5-day incuba ion protocol [11]. Similar findings have been found with different blood culture systems 10 1 48-50]. The advent of matrix-assisted laser desorption ionization-time of flight mass spectro?netry (MALDI-TOF) may allow dramatic improvement in the identification of HACEK bacteria snce blood cultures return positive, in terms of accuracy, and delay [14 18]. - Thirtly, a systematic study on the association between HACEK bacteremia and the probability of endocarditis [4], found striking heterogeneity within the HACEK group: Indeed, the positive predictive value of positive blood culture(s) for the diagnosis of endocarditis ranged from $0 \%$ with E. corrodens bacteremia, to $100 \%$ for A. actinomycetemcomitans.

- Fourthly, a large multi-national, prospective cohort of 5,591 patients with definite infective endocarditis, found that the 77 cases of HACEK endocarditis (1.4\% of the whole cohort), were 
significantly younger (median age, 47 vs. 61 years, $\mathrm{P}<0.001$ ), had more vascular/immunologic manifestations ( $32 \%$ vs. $20 \%, \mathrm{P}<0.008$ ), and stroke ( $25 \%$ vs. $17 \%, \mathrm{P}=0.05$ ), but lower risk of heart failure ( $15 \%$ vs. 30\%, $\mathrm{P}=0.004)$, in-hospital mortality ( $4 \%$ vs. $18 \%, \mathrm{P}<0.001)$, and one-year mortality (6\% vs. 20\%, $\mathrm{P}=0.01$ ) [7]. Importantly, the favourable outcome of both medically and surgically treated HACEK endocarditis on prosthetic valve demonstrates that these organismas are not a stand-alone indication for surgical valvular replacement (i.e. usual criteria for surgical treatment should apply, mostly heart failure, embolism risk, and medical treatment faiiure [22 51]).

- Fifthly, $\beta$-lactamase-producing strains of HACEK may be emerging [19 52], and difficulty in performing antimicrobial susceptibility testing as a result of failure of growth in vitro have led endocarditis experts to recommend that, 'unless growth is adequate for in vitro screening, then HACEK microorganisms should be considered ampicillin resistant, and penicillin and ampicillin should not be used to treat patients with IE in these cases [22]. However, when reliable drugsusceptibility testing demonstrate that amoxicillin or ampiculin are effective in vitro, in the absence of $\beta$-lactamase production, one of these agent mav be used instead of third generation cephalosporin [51], as their narrower spectrum would imply a iswer risk of drug-resistant bacteria selection, and a more limited impact on microbiota - hence a lower risk of Clostridium difficile colitis. The use of aminoglycoside is not recomminder for HACEK endocarditis. Ciprofloxacin is the main alternative in patients who cannoi tolerate $\beta$-lactam agents. The recommended duration of treatment is 4 weeks for native valye endocarditis, and six weeks for prosthetic valve endocarditis.

\section{Five-vear view}

The fjeld of HACEK endocarditis will probably experience limited development over the next 5 years. There is no reason why it would evolve as an emerging disease, given the very low and steady proportion of infective endocarditis that were related to these pathogens since the first descriptions of HACEK endocarditis more than 50 years ago. In addition, the changing profile of infective endocarditis since the early 2000's mostly favours the emergence of staphylococci 
endocarditis, as a consequence of medical progress. Current systems for blood cultures have resolved the need for extended incubation of blood culture bottles for the diagnosis of HACEK endocarditis, and the advent of new tools for rapid identification of bacteria (e.g. MALDI-TOF) have brought additional progress in the field, so that no dramatic improvement is expected to have any significant impact on the diagnosis of HACEK endocarditis over the next five years. Fjndily, current recommendations for treatment will probably not dramatically change as well, given the $100 \%$ susceptibility rate of HACEK bacteria to the first-line regimen currently recommended (third generation cephalosporin), and the favourable outcome in most cases, with the puse of current criteria for surgical valvular replacement. 


\section{Key issues}

- Following 2006 taxonomy changes, HACEK now refers to Haemophilus parainfluenzae, Aggregatibacter spp. (A. actinomycetemcomitans, A. aphrophilus, A. paraphrophilus, and A. segnis), Cardiobacterium spp. (C. hominis, C. valvarum), Eikenella corrodens, and Kingella spp. (K. kingae, K. denitrificans)

- The HACEK bacteria are an heterogeneous group of fastidious, gram-negative bacilli, part of the normal upper respiratory tract microbiota in humans, with limited pathogericity except endocarditis - for most of them

- HACEK are responsible for $1-3 \%$ of all infective endocarditis, and mostly occurs in patients with underlying valve disease

- As compared to other infective endocarditis, HACFK endocuiditis are characterized by an insidious course - hence a prolonged delay before symptoms onset, and diagnosis, in most cases

- As for any other infective endocardlits, the cliagnosis of HACEK endocarditis relies mainly on sampling an adequate vchume of blood for cultures before any antibacterial treatment.

- Continuously monitorear automated blood culture systems with enriched media routinely used in industrialized ceuntres identifies 100\% of HACEK endocarditis within 5 days of incubation

- Unless growth is adequate for in vitro screening, HACEK microorganisms should be coinsidered ampicillin resistant, and a third generation cephalosporin should be preferred for the treatment of HACEK endocarditis. Ciprofloxacin is the main alternative for patients with severe intolerance to all $\beta$-lactams

- No combination of antimicrobials is necessary; treatment duration should be 4 weeks for native valve endocarditis, and 6 weeks for prosthetic valve endocarditis 


\section{Declaration of interest}

The authors have no relevant affiliations or financial involvement with any organization or entity with a financial interest in or financial conflict with the subject matter or materials discussed in the manuscript. This includes employment, consultancies, honoraria, stock ownership or options, expert testimony, grants or patents received or pending, or royalties. 


\section{References}

Papers of special note have been highlighted as: * of interest, or ** of considerable interest

1. Brouqui P, Raoult D. Endocarditis due to rare and fastidious bacteria. Clinical microbiology reviews 2001;14(1):177-207 doi: 10.1128/cmr.14.1.177-207.2001[published Online First: Epub Date]|.

2. Das M, Badley AD, Cockerill FR, et al. Infective endocarditis caused by HACEK microorganisms. Annual review of medicine 1997;48:25-33 doi: 10.1146/annurev.med.48.1.25[published Online First: Epub Date]|.

* A monocentric study of 45 cases of HACEK endocarditis managed in the Mayo clinic during years 1970-1992

3. Duval X, Delahaye F, Alla F, et al. Temporal trends in infective endocarditis in the context of prophylaxis guideline modifications: three successive population-based surveys. Iournal of the American College of Cardiology 2012;59(22):1968-76 doi: 10.1016/j.jacc.2012.02.029[published Online First: Epub Date]|.

4. Yew HS, Chambers ST, Roberts SA, et al. Association between HACFR vacteraemia and endocarditis. Journal of medical microbiology 2014;63(Pt 6):892-5 doi. 10.1099/jmm.0.070060-0[published Online First: Epub Date]|.

** A landmark paper on the positive predictive value of blood cslture(s) yielding HACEK bacteria, for the diagnosis of HACEK endocarditis

5. Yagupsky P. Kingella kingae: carriage, transmission, and disease. Clinical microbiology reviews 2015;28(1):54-79 doi: 10.1128/cmr.00028-14[publisied Online First: Epub Date]|.

* An informative review on the microbiology, the epidemialogy, and the pathophysiology, of Kingella kingae, a fascinating pathogen for pediatricians

6. Selton-Suty C, Celard M, Le Moing V, et al. Preminerice of Staphylococcus aureus in infective endocarditis: a 1-year population-based survey. Clin Infect Dis 2012;54(9):1230-9 doi: 10.1093/cid/cis199[published Online First: Epub Date]|.

7. Chambers ST, Murdoch D, Morris A et al. HACEK infective endocarditis: characteristics and outcomes from a large, muiti-national cohort. PLoS One 2013;8(5):e63181 doi: 10.1371/journal.pone.0563181 Lpublished Online First: Epub Date]|.

** The largest prospective study on HACEK endocarditis from the International Collaboration or Endecardicis (ICE) consortium, with a comparison to non-HACEK infective endo carditis

8. Murdoch DR, Corev GR, Hoen B, et al. Clinical presentation, etiology, and outcome of infective endocarditis in the 21st century: the International Collaboration on Endocarditis-Prospective Cohor Study. Archives of internal medicine 2009;169(5):463-73 doi: 10.1001/archiniernmed.2008.603[published Online First: Epub Date]|.

9. Mark $s$ D, Hyans C, Koo CY, et al. Clinical features, microbiology and surgical outcomes of nfecive endocarditis: a 13-year study from a UK tertiary cardiothoracic referral centre. QIM : monthly journal of the Association of Physicians 2015;108(3):219-29 doi: 10.1093/qjmed/hcu188[published Online First: Epub Date]|.

10. Peti CA, Bhally HS, Weinstein MP, et al. Utility of extended blood culture incubation for isolation of Haemophilus, Actinobacillus, Cardiobacterium, Eikenella, and Kingella organisms: a retrospective multicenter evaluation. J Clin Microbiol 2006;44(1):257-9 doi: 10.1128/jcm.44.1.257-259.2006[published Online First: Epub Date]|.

11. Baron EJ, Scott JD, Tompkins LS. Prolonged incubation and extensive subculturing do not increase recovery of clinically significant microorganisms from standard automated blood cultures. Clin Infect Dis 2005;41(11):1677-80 doi: 10.1086/497595[published Online First: Epub Date]|.

12. Branda JA, Rychert J, Burnham CA, et al. Multicenter validation of the VITEK MS v2.0 MALDI-TOF mass spectrometry system for the identification of fastidious gram-negative 
bacteria. Diagn Microbiol Infect Dis 2014;78(2):129-31 doi:

10.1016/j.diagmicrobio.2013.08.013[published Online First: Epub Date]|.

13. Couturier MR, Mehinovic E, Croft AC, et al. Identification of HACEK clinical isolates by matrix-assisted laser desorption ionization-time of flight mass spectrometry. J Clin Microbiol 2011;49(3):1104-6 doi: 10.1128/jcm.01777-10[published Online First: Epub Date]|.

14. Powell EA, Blecker-Shelly D, Montgomery S, et al. Application of matrix-assisted laser desorption ionization-time of flight mass spectrometry for identification of the fastidious pediatric pathogens Aggregatibacter, Eikenella, Haemophilus, and Kingella. J Clin Microbiol 2013;51(11):3862-4 doi: 10.1128/jcm.02233-13[published Online First: Fpéb Date]|.

15. van Veen SQ, Claas EC, Kuijper EJ. High-throughput identification of bacteria and yeast vy matrix-assisted laser desorption ionization-time of flight mass spectrometry in conventional medical microbiology laboratories. J Clin Microbiol 2010;48(3):900-7 doi: 10.1128/jcm.02071-09[published Online First: Epub Date]|.

16. Nikkari S, Gotoff R, Bourbeau PP, et al. Identification of Cardiobacterium homi his by broadrange bacterial polymerase chain reaction analysis in a case of culture-negative endocarditis. Archives of internal medicine 2002;162(4):477-9

17. Kuhn C, Disque C, Muhl H, et al. Evaluation of commercial universal iRiva gene PCR plus sequencing tests for identification of bacteria and fungi asseciated with infectious endocarditis. J Clin Microbiol 2011;49(8):2919-23 doi: 10.1120/jcm.00830-11[published Online First: Epub Date]|.

18. Norskov-Lauritsen N. Classification, identification, and clinical significance of Haemophilus and Aggregatibacter species with host specificity for hurnans. Clinical microbiology reviews 2014;27(2):214-40 doi: 10.1128/cinr.00103-13[published Online First: Epub Date]|.

19. Coburn B, Toye B, Rawte $P$, et al. Antimicrobilal susceptibilities of clinical isolates of HACEK organisms. Antimicrobial agents andi chemotherapy 2013;57(4):1989-91 doi: 10.1128/aac.00111-13[published Online Lirst: Epub Date]|.

20. Darras-Joly C, Lortholary O, Mainaridi JL, et al. Haemophilus endocarditis: report of 42 cases in adults and review. Haemophilus Entocarditis Study Group. Clin Infect Dis 1997;24(6):1087-94

21. Raza SS, Sultan OW, Sohaii MR. Gram-negative bacterial endocarditis in adults: state-of-theheart. Expert review of anti-infective therapy 2010;8(8):879-85 doi: 10.1586/eri.10.76[published Online First: Epub Date]|.

22. Baddour LM, Wilsen W'R, Bayer AS, et al. Infective Endocarditis in Adults: Diagnosis, Antimicrobial Therapy, and Management of Complications: A Scientific Statement for Healtheaye Professionals From the American Heart Association. Circulation 2015;:132.15):14:35-86 doi: 10.1161/cir.0000000000000296[published Online First: Epub Datej|.

* The 2015 updated American guidelines for the management of infective endocarditis, with a specific session on HACEK endocarditis

23. Norskov-Lauritsen N, Kilian M. Reclassification of Actinobacillus actinomycetemcomitans, Haemophilus aphrophilus, Haemophilus paraphrophilus and Haemophilus segnis as Aggregatibacter actinomycetemcomitans gen. nov., comb. nov., Aggregatibacter aphrophilus comb. nov. and Aggregatibacter segnis comb. nov., and emended description of Aggregatibacter aphrophilus to include V factor-dependent and V factor-independent isolates. International journal of systematic and evolutionary microbiology 2006;56(Pt 9):2135-46 doi: 10.1099/ijs.0.64207-0[published Online First: Epub Date]|.

24. Henderson B, Ward JM, Ready D. Aggregatibacter (Actinobacillus) actinomycetemcomitans: a triple A* periodontopathogen? Periodontology 2000 2010;54(1):78-105 doi: 10.1111/j.1600-0757.2009.00331.x[published Online First: Epub Date]|.

25. Kaplan AH, Weber DJ, Oddone EZ, et al. Infection due to Actinobacillus 
actinomycetemcomitans: 15 cases and review. Reviews of infectious diseases 1989;11(1):46-63

26. Somers CJ, Millar BC, Xu J, et al. Haemophilus segnis: a rare cause of endocarditis. Clin Microbiol Infect 2003;9(10):1048-50

27. Lau SK, Woo PC, Mok MY, et al. Characterization of Haemophilus segnis, an important cause of bacteremia, by 16S rRNA gene sequencing. J Clin Microbiol 2004;42(2):877-80

28. Paturel L, Casalta JP, Habib G, et al. Actinobacillus actinomycetemcomitans endocarditis. Clin Microbiol Infect 2004;10(2):98-118

29. Elster SK, Mattes LM, Meyers BR, et al. Haemophilus aphrophilus endocarditis: review of 23 cases. The American journal of cardiology 1975;35(1):72-9

30. Coll-Vinent B, Suris X, Lopez-Soto A, et al. Haemophilus paraphrophilus endocarditis: case report and review. Clin Infect Dis 1995;20(5):1381-3

31. Han XY, Meltzer MC, Woods JT, et al. Endocarditis with ruptured cerebral anearysm caused by Cardiobacterium valvarum sp. nov. J Clin Microbiol 2004;42(4):1590-5

32. Malani AN, Aronoff DM, Bradley SF, et al. Cardiobacterium hominis endocarditis. I wo cases and a review of the literature. European journal of clinical microbiology \& infectious diseases : official publication of the European Society of Clinicai Micrneinlogy 2006;25(9):587-95 doi: 10.1007/s10096-006-0189-9[published Online First: Epub Date]|.

33. Wormser GP, Bottone EJ. Cardiobacterium hominis: review of nicrobiologic and clinical features. Reviews of infectious diseases 1983;5(4):680-S1

34. Pritchard TM, Foust RT, Cantely JR, et al. Prosthetic valve endocaíditis due to Cardiobacterium hominis occurring after upper gastrointestinal endoscopy. Am J Med 1991;90(4):516-8

35. Le Quellec A, Bessis D, Perez C, et al. Endocarditis due to beta-lactamase-producing Cardiobacterium hominis. Clin Infect Dis 1994; 19(5):994-5

36. Lu PL, Hsueh PR, Hung CC, et al. Infective en tocarditis complicated with progressive heart failure due to beta-lactamase-producing Gardiabacterium hominis. J Clin Microbiol 2000;38(5):2015-7

37. Walkty A. Cardiobacterium hominis endocarditis: A case report and review of the literature. The Canadian journal of infertious ciseases \& medical microbiology = Journal canadien des maladies infectieuses et de la nicrobiologie medicale / AMMI Canada 2005;16(5):293-7

38. Chen M, Kemp M, Bruur NE, et ai. Cardiobacterium valvarum infective endocarditis and phenotypic/moleçiar characterization of 11 Cardiobacterium species strains. Journal of medical microbio!ogy 2011;60(Pt 4):522-8 doi: 10.1099/jmm.0.025353-0[published Online First: Epub Date]|.

39. Sheng WS, Hsueh PIR, Hung CC, et al. Clinical features of patients with invasive Eikenella corrodens infections and microbiological characteristics of the causative isolates. European journal of flinical microbiology \& infectious diseases : official publication of the European Seciety of Clinical Microbiology 2001;20(4):231-6

40. Taian DA, Abrahamian FM, Moran GJ, et al. Clinical presentation and bacteriologic analysis of infected human bites in patients presenting to emergency departments. Clin Infect Dis 2003,37(11):1481-9 doi: 10.1086/379331[published Online First: Epub Date]|.

41. Gonzalez MH, Garst J, Nourbash P, et al. Abscesses of the upper extremity from drug abuse by injection. The Journal of hand surgery 1993;18(5):868-70 doi: 10.1016/03635023(93)90056-9[published Online First: Epub Date]|.

42. Yagupsky P. Outbreaks of Kingella kingae infections in daycare facilities. Emerg Infect Dis 2014;20(5):746-53 doi: 10.3201/eid2005.131633[published Online First: Epub Date]|.

43. Feder HM, Jr., Roberts JC, Salazar J, et al. HACEK endocarditis in infants and children: two cases and a literature review. The Pediatric infectious disease journal 2003;22(6):557-62 doi: 10.1097/01.inf.0000069795.12338.cf[published Online First: Epub Date]|.

\section{* An interesting review on HACEK endocarditis in children}

44. Yagupsky P, Ben-Ami Y, Trefler R, et al. Outbreaks of Invasive Kingella kingae Infections in 
Closed Communities. The Journal of pediatrics 2015 doi:

10.1016/j.jpeds.2015.10.025[published Online First: Epub Date]|.

45. Tleyjeh IM, Abdel-Latif A, Rahbi H, et al. A systematic review of population-based studies of infective endocarditis. Chest 2007;132(3):1025-35 doi: 10.1378/chest.06-2048[published Online First: Epub Date]|.

46. Tattevin P, Watt G, Revest M, et al. Update on blood culture-negative endocarditis. Medecine et maladies infectieuses 2015;45(1-2):1-8 doi: 10.1016/j.medmal.2014.11.003[published Online First: Epub Date]|.

* A recent update on blood culture negative endocarditis

47. Berbari EF, Cockerill FR, 3rd, Steckelberg JM. Infective endocarditis due to unusual or fastidious microorganisms. Mayo Clinic proceedings 1997;72(6):532-42 doi: 10.1016/s0025-6196(11)63302-8[published Online First: Epub Date]|.

48. Weinstein MP. Emerging data indicating that extended incubation of blood cultares has litile clinical value. Clin Infect Dis 2005;41(11):1681-2 doi: 10.1086/497603[nublished Oriline First: Epub Date]|.

** A landmark editorial with a summary of data advocating that extended incubation of blood cultures has little clincial value for the diagnosis of HA.CEK endocarditis

49. Doern GV, Davaro R, George M, et al. Lack of requirement for prolongeủ ir cubation of SeptiChek blood culture bottles in patients with bacteremia due to fastidious bacteria. Diagn Microbiol Infect Dis 1996;24(3):141-3

50. Wilson ML, Mirrett S, Reller LB, et al. Recovery of clinicaliv important microorganisms from the BacT/Alert blood culture system does not require testing for seven days. Diagn Microbiol Infect Dis 1993;16(1):31-4

51. Habib G, Lancellotti P, Antunes MJ, et al. 2015 ESS Guidelanes for the management of infective endocarditis: The Task Force for the Management of Infective Endocarditis of the European Society of Cardiology (ESC)Endirsed by: European Association for CardioThoracic Surgery (EACTS), the European Association of Nuclear Medicine (EANM). European heart journal 2015;36(44):3e75-123 doi: 10.1093/eurheartj/ehv319[published Online First: Epub Date]|.

52. el Khizzi N, Kasab SA, Osoba A O. HACEK group endocarditis at the Riyadh Armed Forces Hospital. J Infect 1997;34; $; \div 69-74$ 
Table 1. Characteristic features of HACEK organisms causing endocarditis

\begin{tabular}{|c|c|c|c|c|c|}
\hline Organism & $\begin{array}{l}\text { Microbiology } \\
\text { (family, gram) }\end{array}$ & Pathogenicity in Humans & $\begin{array}{l}\text { Epidemiology of } \\
\text { endocarditis }\end{array}$ & $\begin{array}{l}\text { Characteristics of } \\
\text { endocarditis }\end{array}$ & Outcome \\
\hline $\begin{array}{l}\text { Haemophilus } \\
\text { parainfluenzae }\end{array}$ & $\begin{array}{l}\text { Pasteurellaceae } \\
\text { pleomorphic gram- } \\
\text { negative } \\
\text { coccobacilli }\end{array}$ & $\begin{array}{l}\text { 55\% of patients with positive BC have } \\
\text { endocarditis } \\
\text { Other infections rare: respiratory tract, brain } \\
\text { abscess, soft tissue, prosthetic joint, biliary } \\
\text { tract, neonatal sepsis }\end{array}$ & $\begin{array}{l}\text { 27-36\% of all HACEK } \\
\text { endocarditis } \\
\text { Risk factors: underlying } \\
\text { heart disease (60\%), } \\
\text { prosthetic valve (12\%), } \\
\text { IVDU }\end{array}$ & $\begin{array}{l}\text { Moterately insidious (mean } \\
\text { curation of symptoms before } \\
\text { diagnosis, } 35 \text { days) } \\
\text { Mostly mitral valve }(71 \%)\end{array}$ & $\begin{array}{l}\text { Cardiac surgery, } \\
40-70 \% \\
\text { Mortality, } \\
5-10 \%\end{array}$ \\
\hline $\begin{array}{l}\text { Aggregatibacter spp. } \\
\text { A. actinomycetemcomitans } \\
\text { A. aphrophilus } \\
\text { A. paraphrophilus } \\
\text { A. segnis }\end{array}$ & $\begin{array}{l}\text { Pasteurellaceae } \\
\text { pleomorphic gram- } \\
\text { negative } \\
\text { coccobacilli }\end{array}$ & $\begin{array}{l}100 \% \text { of patients with positive BC for } A \text {. } \\
\text { actinomycetemcomitans and } A \text {. } \\
\text { paraphrophilus have endocarditis } \\
\text { Other infections rare: abscesses, association } \\
\text { with Actinomycetes, endophtalmitis, bone and } \\
\text { joint }\end{array}$ & $\begin{array}{l}\text { 34-36\% of all HACEK } \\
\text { endocarditis } \\
\text { Risk factors: tncierlying } \\
\text { heât disease ( } 5 \%) \text {, } \\
\text { prosthetic valve }(26 \%) \\
\text { Dentai disease }(42 \%)\end{array}$ & $\begin{array}{l}\text { A. actinomycetemcomitans } \\
\text { Very insidious (mean } \\
\text { duration of symptoms before } \\
\text { diagnosis, } 100 \text { days) } \\
\text { Mostly aortic ( } 51 \%) \text {, or } \\
\text { mitral valve (33\%) }\end{array}$ & $\begin{array}{l}\text { Cardiac surgery, } \\
25 \% \\
\text { Mortality, } \\
18 \%\end{array}$ \\
\hline $\begin{array}{l}\text { Cardiobacterium spp. } \\
\text { C. hominis } \\
\text { C. valvarum }\end{array}$ & $\begin{array}{l}\text { Cardiobacteriaceae } \\
\text { pleomorphic gram- } \\
\text { negative or gram- } \\
\text { variable bacilli } \\
\end{array}$ & $\begin{array}{l}\text { 88-95\% of patients with positive BC for } \\
\text { Cardiobacterium hominis have endocarditis } \\
\text { Very low virulence in animals } \\
\text { No other infection }\end{array}$ & $\begin{array}{l}\text { 14-27\% of all HACEK } \\
\text { enciorarditis } \\
\text { Risk factors: underlying } \\
\text { heart disease }(61 \%) \text {, } \\
\text { prosthetic valve }(28 \%)\end{array}$ & $\begin{array}{l}\text { The most insidious (mean } \\
\text { duration of symptoms before } \\
\text { diagnosis, } 138-169 \text { days) } \\
\text { Mostly aortic }(52 \%) \text {, or } \\
\text { mitral valve }(44 \%)\end{array}$ & $\begin{array}{l}\text { Cardiac surgery, } \\
45 \% \\
\text { Mortality, } \\
7 \% \\
\end{array}$ \\
\hline Eikenella corrodens & $\begin{array}{l}\text { Neisseriaceae } \\
\text { pleomorphic gram- } \\
\text { negative bacilli }\end{array}$ & $\begin{array}{l}\text { 0/11 patients with positive BC for } \\
\text { corrodens had endocarditis in ont study } \\
\text { E. corrodens is involved in a broad snectrum } \\
\text { of infectious diseases: i) in IVDU (soft tissue, } \\
\text { endovascular); ii) traunatic noculation } \\
\text { (human bites, cleiched fist injuries) }\end{array}$ & $\begin{array}{l}\sim 5 \% \text { of all HACEK } \\
\text { endocarditis }\end{array}$ & Limited data (no series) & $\begin{array}{l}\text { Limited data } \\
\text { (no series) }\end{array}$ \\
\hline $\begin{array}{l}\text { Kingella spp. } \\
\text { K. kingae } \\
\text { K. denitrificans }\end{array}$ & $\begin{array}{l}\text { Neisseriaceae } \\
\text { small gram- } \\
\text { negative } \\
\text { coccobacilli }\end{array}$ & $\begin{array}{l}\text { 8/19 patient }(42 \%) \text { with } \\
\text { kingae had endive BC for } K \text {. } \\
\text { First cause of septic arthritis in children }<2 \\
\text { years of age, and a common cause of occult } \\
\text { bacteremia in this population }\end{array}$ & $\begin{array}{l}\text { 5-7\% of all HACEK } \\
\text { endocarditis } \\
36 \% \text { of all HACEK } \\
\text { endocarditis in children } \\
\text { (underlying heart } \\
\text { disease, } 62 \% \text { ) } \\
\end{array}$ & Limited data (no series) & $\begin{array}{l}\text { Cardiac surgery, } \\
23 \% \\
\text { Mortality, } \\
8 \%\end{array}$ \\
\hline
\end{tabular}

HACEK microorganisms: Haemophilus parain.flyenzae, Äggregatibacter spp., Cardiobacterium spp., Eikenella corrodens, and Kingella spp.

BC: blood cultures; IVDU: intravenous drug use 